\title{
Determining critical factors to avoid failures in the building process
}

\author{
G.W. Dijkshoorn, K.C. Terwel \& F.W. Guldenmund \\ Delft University of Technology, Delft, The Netherlands
}

\begin{abstract}
During the last few years, several major accidents during the construction phase have occurred in the Dutch building industry. The collapse of a roof structure of the FC Twente football stadium and the collapse of a concrete floor of the B-tower Rotterdam are some recent examples. Consequently, Dutch contractors do need to establish a reliable building process to prevent this kind of accidents.

The main research question of this study was: "Which factors in the design and construction process influence structural safety at a single company?" Based on a previously published list of possible critical factors for a building project (Terwel \& Vambersky, 2012), a questionnaire was developed in which 61 participants rated the contribution of these possible factors on structural safety in successful and in less successful projects on a five point Likert scale. Significant differences in the rating between successful and less successful projects indicated the relative influence of the specific factor on structural safety.

Statistical analysis showed that Collaboration, Allocation of responsibilities, Risk analysis and allocation, Communication, Safety culture, Control mechanisms and Knowledge infrastructure were the most influencing factors concerning structural safety. The company was advised to improve these factors to reduce the number of failures in their construction processes in the future.
\end{abstract}

\section{INTRODUCTION}

During the last few years, several major accidents during the construction phase have occurred in the Dutch building industry. The failure of a roof structure of the FC Twente football stadium (De Onderzoeksraad voor Veiligheid, 2012) and the collapse of a concrete floor of the B-tower Rotterdam (De Onderzoeksraad voor Veiligheid, 2012) are some recent examples. In both projects communication and control mechanisms within hired subcontractors failed during the construction phase.

Some other EU countries had to deal with similar problems. The collapse of a terminal of Charles de Gaulle airport near Paris (France) in 2004 and the city archives of Cologne (Germany) in 2009 are two international examples.

Consequently, contractors need to establish a reliable building process to prevent these kinds of accidents. To achieve this, process factors influencing structural safety have to be known.

\section{RESEARCH PLAN}

Themain researchquestion of thisstudywas: "Which factors influence structural safety in the design and construction process at a single company?".
In this study, a structure is regarded to be safe when it is resistant to all forces to which a building is exposed during its lifetime.

To answer the main research question, we firstly had to know which factors are possible critical factors with regard to structural safety in the design and construction phase of a building project. Secondly, we developed a questionnaire to determine the real critical factors in the building process, based on a list of possible critical factors. And finally, we had to administer the questionnaire and analyze the results.

\subsection{Possible critical factors}

The factors that have been used in the questionnaire are based on a previously published list of possible critical factors regarding structural safety in the design and construction phase of a building project (Terwel \& Vambersky, 2012). These factors can be categorized at sector/country (macro) level, project or company (meso) level and individual (micro) level. Macro level consists of external factors; these factors describe the situation in which the project is carried out. Meso level consists of project and company factors (collaboration, safety culture, protocols, etc.). Similar factors might be applicable at the company and project organization, because both are a group of individuals who will have to work 
to together to reach a collective goal. Within one company all individuals have the same employer. A project team consists of all advisors and (sub) contractors; working together could be more complicated in this situation. Micro level consists of human factors (skills, competencies, etc.). Project characteristics, e.g. complexity of the project, might influence the outcome of significantly influencing factors and will be included separately. Figure 1 shows all possible critical factors at macro, meso and micro level and project characteristics.

\subsection{Questionnaire}

We have developed a questionnaire to determine the real critical factors, based on a list of possible

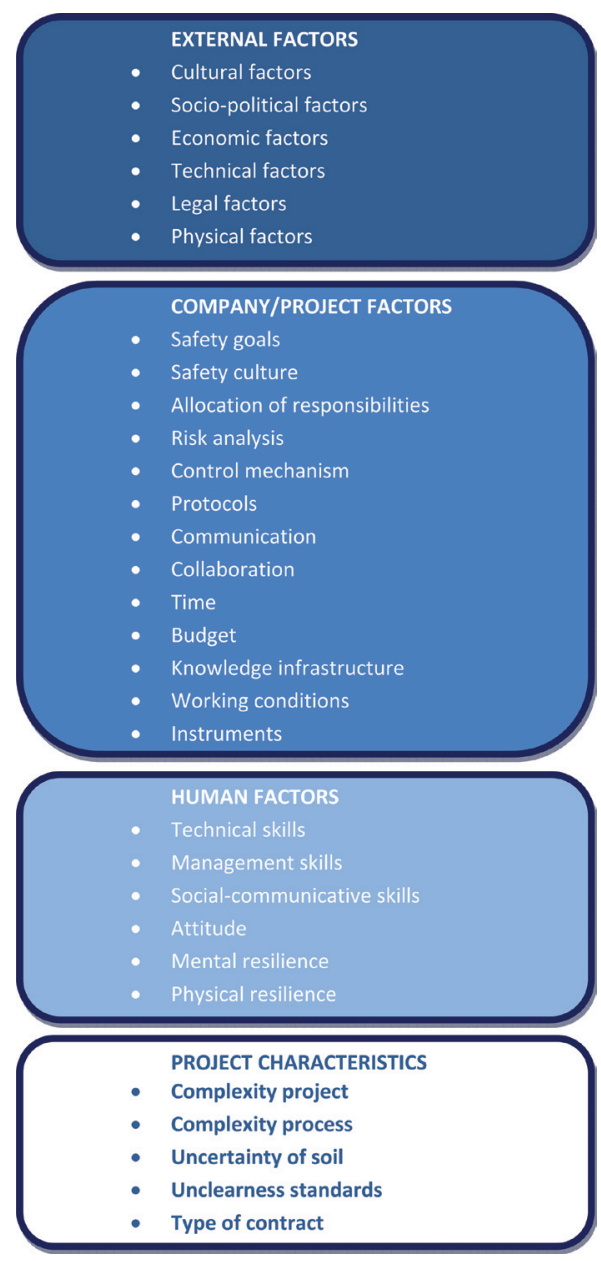

Figure 1. Possible critical factors at macro, meso and micro level and project characteristics (Terwel \& Vambersky, 2012). critical factors. This questionnaire consisted of two parts. In the first part the respondents were asked to rate the presence of the possible factors impacting structural safety in successful and in less successful projects on a five point Likert scale (fully disagree-disagree-neutral-agree-fully agree). The answers had to be based on the experience of the respondents, gained during successful and less successful projects. A significant difference in the rating between successful and less successful projects indicates the relative influence of that factor on structural safety.

A successful project is in this study defined as a project without (near) major damage during the whole process; no calculation, communication, etc. mistakes are made from which major damage easily could arise. A less successful project is a project with (near) major damage because of insufficient communication, calculation mistakes, etc. during engineering and/or construction. Major damage indeed has occurred or could have easily occurred.

In the second part the participants were asked to choose their top three critical factors regarding structural safety in the building process. The factors with the highest number of votes were regarded to be the most influential on structural safety.

Finally, we have analyzed the results of the questionnaire and compared the results of both questionnaire parts.

\section{RESEARCH AT CONTRACTOR}

\subsection{Contractor description}

This research focused on structural safety performance of a single contractor. The contractor belongs to the top three largest onshore contractors in the Netherlands, especially in design and build projects. During these design and build projects this contractor is responsible for the entire project, from the pre design to the construction phase. Because of the large number of (sub) contractors the main contractor has to deal with fragmentation of responsibilities, miscommunication, incomplete information transfer, etc. during the design, engineering and construction phases. Nevertheless, the contractor needs to guarantee structural safety. On the one hand to guarantee the safety of the employees (of subcontractors), on the other hand to prevent image damage and repair costs.

\subsection{Contractor research plan}

To determine the critical factors in the design and construction phase for this contractor, the research plan was carried out involving a cross-section of 
employees of the contractor. Overall, 61 employees related to the contractor have filled in the questionnaire. Table 1 highlights some characteristics of the respondents. It can be seen that the respondents are highly experienced because about $80 \%$ had over ten years of experience within the construction sector.

We were primarily interested in the levels that can be influenced by the contractor itself. This is the reason why the questionnaire merely focused on meso and micro level, as the macro level is outside the scope of the contractor's organization.

Table 1. Personal characteristics of the 61 participants.

\begin{tabular}{ll}
\hline Personal characteristics & Frequency \\
\hline Employer & $83.8 \%$ contractor \\
& $16.4 \%$ partner \\
Function & $42.6 \%$ design team \\
& $54.1 \%$ construction team \\
& $3.3 \%$ management team \\
Age & $8.2 \% 20-29$ years old \\
& $39.3 \% 30-39$ years old \\
& $21.3 \% 40-49$ years old \\
& $24.6 \% 50-59$ years old \\
& $6.6 \% 60-69$ years old \\
Work experience & $9.8 \% 0-4$ year \\
construction industry & $13.1 \% 5-9$ year \\
& $27.9 \% 10-19$ year \\
& $19.7 \% 20-29$ year \\
Employment & $29.5 \% 30-39$ year \\
& $14.8 \% 0-4$ year \\
& $23.0 \% 5-9$ year \\
& $24.6 \% 10-19$ year \\
& $23.0 \% 20-29$ year \\
& $14.8 \% 30-39$ year
\end{tabular}

\subsection{Results}

The analyses of the responses have been carried out using several statistical tests. Because a Likert scale provides results at the ordinal level of measurement, nonparametric tests have been applied, i.e. the Mann-Whitney, Pearson Chi-square, Wilcoxon signed and Cochran's Q tests as well as Spearman's rank correlation test have been used to test the significance of our findings (Moore \& McCabe, 2003). In all tests the difference between a successful project and less successful project are verified statistically. Level of significance is a statistical criterion that is used to decide whether the outcome of an experiment is the result of an assumed relationship between specific factors or merely the result of chance. A significance level of $p<0.05$ means that the probability of an event occurring by chance is less than five percent.

\subsubsection{Difference successful and less successful projects}

The statistical analysis of the first part of the questionnaire showed differences between successful and less successful projects, at a meso and micro level. The statistical analysis showed that seven project factors at a meso level are the most influencing factors concerning structural safety (Delta $>0,6$ ). For this particular contractor the project factors Collaboration, Allocation of responsibilities, Risk analysis and allocation, Communication, Safety culture, Control mechanisms and Knowledge infrastructure are the determining factors (all $p<0.05$ ). The results are presented in Figure 2, more detail information in Tables 2 and 3.

Figure 2 and Tables 2 and 3 show that the differences at a project level are larger than at a company

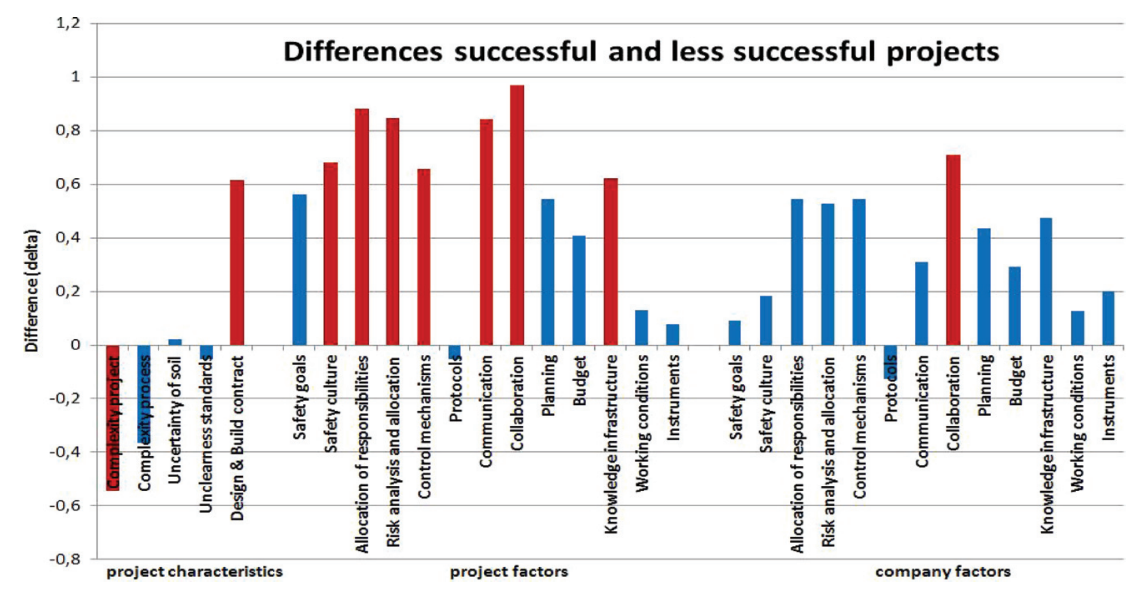

Figure 2. Presence difference of project characteristics and critical project and company factors on meso level between successful and less successful projects. 
Table 2. Rank of critical project factors at the meso level within the building process $(*=p<0.05)$.

\begin{tabular}{lc}
\hline Rank project factors & Score differences \\
\hline Collaboration & $0.97^{*}$ \\
Allocation of responsibilities & $0.88^{*}$ \\
Risk analysis and allocation & $0.85^{*}$ \\
Communication & $0.84^{*}$ \\
Safety culture & $0.68^{*}$ \\
Control mechanisms & $0.66^{*}$ \\
Knowledge infrastructure & $0.62^{*}$ \\
Safety goals & $0.56^{*}$ \\
Planning & $0.54^{*}$ \\
Budget & $0.41^{*}$ \\
Working conditions & 0.13 \\
Instruments & 0.08 \\
Protocols & -0.05 \\
\hline
\end{tabular}

Table 3. Rank of critical company factors at the meso level within the building process $(*=p<0.05)$.

\begin{tabular}{lc}
\hline Rank company factors & Score differences \\
\hline Collaboration & $0.71^{*}$ \\
Allocation of responsibilities & $0.55^{*}$ \\
Control mechanisms & $0.55^{*}$ \\
Risk analysis and allocation & $0.53^{*}$ \\
Knowledge infrastructure & $0.47^{*}$ \\
Planning & $0.44^{*}$ \\
Communication & $0.31^{*}$ \\
Budget & $0.29^{*}$ \\
Instruments & $0.2^{*}$ \\
Safety culture & 0.18 \\
Working conditions & 0.13 \\
Safety goals & 0.09 \\
Protocols & -0.13 \\
\hline
\end{tabular}

level. The largest delta values are colored red in Figure 2. We can conclude that the presence of critical factors at the project level is more influential with regard to structural safety than at a company level. The level of significance of the differences between successful and less successful projects in Tables 2 and 3 is verified using the Wilcoxon signed ranks test (Moore \& McCabe, 2003).

The negative result of using protocols in Tables 2 and 3 shows that using protocols seems to have a small negative influence on structural safety. Because this result is not significant, we cannot base any firm conclusion on this outcome. According to several Dutch accident investigation reports the use of protocols is an important factor to realize reliable project management (De Onderzoeksraad voor Veiligheid, 2012).

According to Figure 2, project characteristics can influence structural safety. For this specific contractor an increase in the complexity of projects $(Z=-3.12, p<0.05)$ and of processes $(Z=-1.88$, $p>0.05)$ resulted relatively often in less successful projects. The use of design and build contracts resulted in a relatively higher number of successful projects than a traditional separate engineering and build project $(Z=2.57, p<0.05)$.

The results of human factors are shown in Table 4. The score differences are smaller for Human factors than for Project factors. Technical skills and Attitude are the most influencing factors at the individual (micro) level.

The correlation between factors and/or project characteristics is relatively small, the highest rank correlation coefficients are mentioned below. A Complex process and Complex project results relatively often in a higher score on Safety goals (Spearman's rho $=0.49$ and rho $=0.42, p<0.05$ ). The strongest correlation between project factors is found between the factors Communication and Collaboration (Spearman's rho $=0.67, p<0.05$ ) These factors seems to be closely related to each other. Finally, individual factors have a small correlation (rho $=0.35$ to 0.60 , all $p<0.05$ ) with the project factor Collaboration.

It was checked if there was a difference between the experiences of employees working primarily in the design phase compared to employees working in the construction phase. A Mann-Whitney test was used to test the difference in experience between design and construction team members (Moore \& McCabe, 2003). In case of a successful project the construction team members have a more positive experience regarding the factors Safety culture $(Z=-3,36, p<0.05)$, Working conditions $(Z=-2.15, p<0.05)$ and Social communication skills $(Z=-2.29, p<0.05)$. In case of a less successful project the design team members have a more negative experience regarding the factors Complexity of process $(Z=-2.05, p<0.05)$ and Time $(Z=-2.50, p<0.05)$.

\subsubsection{Opinion of employees}

Statistical tests were carried out to determine important factors according to the opinion of

Table 4. Rank of critical factors at the micro level within the building process $(*=p<0.05)$.

\begin{tabular}{ll}
\hline Rank human factors & Score differences \\
\hline Technical skills & $0.59^{*}$ \\
Attitude & $0.53^{*}$ \\
Management skills & $0.49^{*}$ \\
Social-communicative skills & $0.44^{*}$ \\
Mental resilience & $0.43^{*}$ \\
Physical resilience & $0.24^{*}$ \\
\hline
\end{tabular}


Table 5. Structural safety influence per critical factor according to the opinion of the respondents.

\begin{tabular}{ll}
\hline Rank possible critical factors & Number of votes \\
\hline Risk analysis and allocation & 43 \\
Allocation of responsibilities & 32 \\
Control mechanisms & 21 \\
Safety culture & 17 \\
Communication & 16 \\
Collaboration & 13 \\
Knowledge infrastructure & 12 \\
Planning & 9 \\
Safety goals & 8 \\
Protocols & 7 \\
Budget & 4 \\
Working conditions & 0 \\
Instruments & 0 \\
\hline
\end{tabular}

Table 6. Top 7 critical projects factors in questionnaire part 1 and 2.

\begin{tabular}{ll}
\hline Top 7 project factors part 1 & Top 7 factors part 2 \\
\hline Risk analysis and allocation & Collaboration \\
$\begin{array}{l}\text { Allocation of } \\
\text { responsibilities }\end{array}$ & Allocation of \\
responsibilities \\
Control mechanisms & Risk management \\
Safety culture & Communication \\
Communication & Safety culture \\
Collaboration & Control mechanisms \\
Knowledge infrastructure & Knowledge infrastructure \\
\hline
\end{tabular}

the employees. The project factor Risk analysis is by far the most influencing factor with regard to structural safety. Number of votes per critical factor are showed in Table 5. All differences between the number of votes per factor are significant $(p<0.05)$, according to a Cochran's Q test (Moore \& McCabe, 2003).

A Pearson Chi-square test was used to test the difference in opinion between design and construction team members (Moore \& McCabe, 2003). Construction workers chose the factor Safety culture twice as much as the designers $(p<0.05)$. The factors Time, Budget and Knowledge infrastructure are more often chosen by the designers. However, these differences are not significant (all $p>0.05$ ). The factor Risk analysis and allocation is the factor chosen most by both groups. Comparison of part 1 and 2 of survey

To come to a balanced result, we have compared the results of the statistical analyses of part 1 and 2 . Table 6 compares the seven most critical factors, from both parts of the questionnaire. It can be seen that these factors are very similar.

\subsubsection{Discussion}

Some remarks on the approach can be made. Questionnaires have some drawbacks and are limited in the reliability of the outcomes. It is necessary to carry out additional interviews (Yin, 2009) and collect additional data to understand if the factors derived really describe the problems experienced. Secondly, it is possible that other factors than those included in the list are equally important in influencing structural safety.

\subsection{Recommendations to the contractor}

The company was recommended to improve the factors Risk analysis and allocation, Allocation of responsibilities, Control mechanisms, Safety culture, Communication, Collaboration and Knowledge infrastructure to reduce the number of failures in their construction processes in the future. It is important to improve these factors without losing attention for other factors. Otherwise other factors could become critical factors in the future.

\section{CONCLUSION}

For a Dutch contractor the most influencing factors regarding structural safety have been derived by using a questionnaire. According to the respondents these factors are Risk analysis and allocation, Allocation of responsibilities, Control mechanisms, Safety culture, Communication, Collaboration and Knowledge infrastructure. When these factors are improved it is expected that the performance of this contractor regarding structural safety will improve.

The questionnaire method is a useful and a powerful tool to collect data based on professionals' experience within a short time span. However, it is necessary to carry out additional interviews (Yin, 2009) and acquire additional data to understand if the factors derived really describe the problems experienced.

When this assessment is carried out at several companies within the Dutch building industry, benchmarking is also possible. When a major number of companies will work on the factors influencing structural safety, it is believed that the level of structural safety within The Netherlands will improve in the future.

\section{REFERENCES}

De Onderzoeksraad voor Veiligheid, 2012. Instorten van het dak van de aanbouw van het stadion van FC Twente, te Enschede. Den Haag. 
De Onderzoeksraad voor Veiligheid, 2012. Instorting verdiepingsvloer B-tower Rotterdam. Den Haag.

Moore, D.S. \& McCabe, G.P., 2003. Introduction to the Practice of Statistics. New York, W.H. Freeman and Company.

Terwel, K.C. \& Vambersky, J.N.J.A., 2012. Possible critical structural safety factors: a literature review. Forensic Engineering 2012: Gateway to a safer tomorrow. Dolhon, A.M. San Fransisco: ASCE.
Yin, R.K., 2009. Case Study Research, Design and Methods. Thousand Oaks, SAGE Inc. 